\title{
Comparing the Effect of Spiritual Intelligence and Personal Intelligence Training on Compatibility, Accountability, and Legitimacy in 14-16-Year-old Students
}

\author{
Firooz Tizro Toly ${ }^{1}$, Tavakkol Mousazadeh ${ }^{2 *}$, Reza Kazemi ${ }^{3}$ (D) \\ 1 PhD student, Educational Psychology, Department of Psychology, Ardabil Branch, Islamic Azad University, Ardabil, Iran \\ 2 PhD, Assistant Professor, Department of Psychology, Ardabil Branch, Islamic Azad University, Ardabil, Iran \\ ${ }_{3}$ PhD, Assistant Professor, Department of Psychology, Islamic Azad University, Ardabil Branch, Ardabil, Iran
}

*Corresponding author:

Tavakkol Mousazadeh, Assistant Professor, Department of Psychology, Islamic Azad University, Ardabil

Branch, Ardabil, Iran

Tel: 09111845287

Email: T.mousazadeh@iauardabil.ac.ir

Received: 07 Oct. 2019

Accepted: 26 Feb. 2020

ePublished: 01 May. 2020

\begin{abstract}
Background and Objective: Personal intelligence is the ability to understand and regulate emotions relying on a sense of self-awareness. The present study aimed to compare the effect of spiritual intelligence and personal intelligence training on the adaptability, responsibility, and legitimacy of students.

Materials and Methods: This experimental study was conducted based on a pre-posttest design with a control group. The statistical population of the study included 160 individuals within the age range of 14-16 years in the academic year 2018. In the current study, the education office of the region called for cooperation, and 60 students were selected by random sampling from among the volunteers who were willing to participate. The participants were assigned to three groups of spiritual intelligence $(n=20)$, personal intelligence $(n=20)$, and control group $(n=20)$; thereafter, the experimental groups were subjected to 10 training sessions. The data collection instruments included the social compatibility questionnaire developed by Pekol and Weisman and responsibility and legitimacy questionnaire designed by Alipour. The obtained data were analyzed in SPSS software using multivariate covariance.

Results: As evidenced by the results of the current study, spiritual intelligence and personal intelligence training had a significant impact on compatibility, responsibility, and legitimacy of students $(\mathrm{P}<0.05)$. Two-by-two comparison of intervention methods of spiritual intelligence and personal intelligence training indicated that personal intelligence training improved students' compatibility, responsibility, and legitimacy. Furthermore, it was found that spiritual intelligence is more effective in the enhancement of compatibility status, compared to personal intelligence.

Conclusion: It can be concluded that spiritual intelligence and personal intelligence training increased the compatibility, accountability, and legitimacy of 14-16-year-old students.

Keywords: Intelligence, Social responsibility, Spiritualism, Students
\end{abstract}

\section{Background}

Much of human development depends on personal and social education; therefore, life's biggest challenges may arise from lack of training on personal and social skills, such as the inability to adapt, be accountable, and abide by the law in human society [1]. Deficiencies in the education system are considered a threat to the survival of society. Sometimes many communities are at risk of disintegration due to inadequate training of community members, incompatibility, irresponsibility, and failure to abide by the law. Incompatibilities, irresponsibility, and failure to abide by the law in a society disrupt personal life and family relationships, endanger school-family unity, and ultimately lead to its dissolution [2]. Adaptability, responsibility, and legitimacy of students are of utmost importance in society.
Compatibility which is one of the most valuable blessings in life is a progressive and ever-evolving process that occurs over time, beginning with birth and ending with death. Human survival and health as an open system depends on compatibility with new conditions. It is a process in which one uses all or some of the adaptive mechanisms to counter new stimuli [3]. Compatibility is the formation of human behavior, and men act by shaping behavioral reactions to maintain their internal and external environmental states. Spirituality which is a coping strategy against illness brings about psychosocialcultural compatibility [4]. Based on related studies, spiritual intelligence exerts positive effects on health and well-being compatibility [5,6]. In this regard, spiritual intelligence training has been shown to have positive effects on the enhancement of social, 
emotional, and family adjustments in female patients with breast cancer. Moreover, social compatibility showed a significant positive correlation with spiritual intelligence and its components [7].

In multiple studies, personal intelligence has been identified as one of the most powerful and influential factors affecting students' compatibility regarding individual, social, educational, and academic behavior [8]. Moreover, these studies denoted that personal intelligence is a strong predictor of adolescent compatibility and a suitable resource for preventive interventions. The correlation between personal intelligence and students' average test scores can demonstrate the importance of personal intelligence in students' academic compatibility. Regarding the relationship between personal intelligence and educational compatibility, the results showed that the highest frequency of students with personal intelligence of $0.15 \%$ had desirable educational compatibility, while the highest frequency of students with lower personal intelligence was reported to have weak educational intelligence. It can be concluded that there is a significant correlation between personal intelligence and educational compatibility, and those students with higher personal intelligence have better educational compatibility [9].

Personal intelligence is related to people's awareness regarding themselves, relationships with others, compatibility, and adjustment with the environment that is required to meet social needs [10]. Accountability is one of the basic and necessary skills for each individual. The role of this skill in social and personal life has been studied by scientists, especially psychologists [11]. Families are central in the initiation of accountability as children grow and undergo the process of socialization. After the child enters the school, the educational institutions are responsible for the enhancement of this skill in the social growth of the child. During the past few decades, accountability and creating this skill in adolescents have received special attention [12]. Types of accountability are as follows: human responsibility toward God, family, and nature [13].

One of the most important organizations in today's world is the Ministry of Education which is responsible for human resources training. Accordingly, the employees of this organization have a special role and place among other organizations. They enter the organization with their different styles of thinking and intelligence and can influence their students by resorting to specific styles of thinking and intelligence [14]. Responsibility is a personality trait that is usually formed as an attitude in the individual's psychological and behavioral structure. This variable is considered to be a key factor in social behavior; therefore, it has a significant place in the training of social behaviors [15]. Accountability in social and personal dimensions is a concept that can be used as a good instrument for the maintenance of social cohesion while respecting and understanding the existing differences. Personal intelligence is the power of self-regulating emotions, which is the ability to rely on a sense of self-awareness, including one's capacity to soothe him/herself, relieve anxieties, depression, or common insomnia, and the consequences of failure in this emotional skill [16]. People with this ability express a sense of responsibility since they are constantly confronted with feelings of frustration and depression, while people who have higher personal intelligence can more quickly overcome the disadvantages of life. Personal intelligence fosters responsibility since it creates inner satisfaction, nurtures inner discipline, and builds strong inner motivation. Furthermore, this intelligence promotes thinking, creates a spirit of joy and vitality, reduces the cost of living, and enhances cognitive ability. Moreover, it helps people attend to and embraces family, groups, and community, and gain confidence [17].

Therefore, due to the absence of research in this field at the country level, the present study strived to answer this question: Are spiritual intelligence and personal intelligence influential on compatibility, accountability, and legitimacy of students?

\section{Objectives}

The present study aimed to compare the effect of spiritual intelligence and personal intelligence training on the adaptability, responsibility, and legitimacy of students.

\section{Materials and Methods}

This experimental study was conducted based on a pre-posttest design with a control group. The statistical population of this study consisted of 160 students within the age range of 14-16 years in the academic year 2018 in Talesh junior and senior high schools. In the current study, Talesh Education Office called for cooperation, and 60 students were selected by random sampling from among the volunteers who were willing to participate. They were randomly assigned to three groups: experimental 1.spiritual intelligence $(n=20)$, experimental 2.personal intelligence $(n=20)$, and control group $(n=20)$. Moreover, in order to comply with research ethics, the participants were provided with all ethical requirements, including the purpose of the research, confidentiality of 
information, freedom of individuals to quit the research if they wish.

After the samples were randomly assigned to three groups (experimental groups 1 and 2, and control group), the three groups were subjected to the first pre-test using Social Compatibility Questionnaire developed by Pekol and Wisman [18] and Responsibility and Legitimacy Questionnaire designed by Alipour [19]. Thereafter, the experimental groups 1 and 2 received ten one-hour sessions of spiritual intelligence intervention taken from research performed by Zohar and Marshall [20], Emmons [21] and Sisk and Torrance [22] spiritual intelligence training sessions, as well as personal intelligence intervention sessions taken from a study conducted by Martin and Rippon [23]. After the end of the educational interventions, the experimental groups were subjected to the post-test, and the obtained data were analyzed in SPSS software using the multivariate analysis of covariance.

Spiritual intelligence training began for the intervention group as ten 90-minute weekly sessions in 2 months using spiritual intelligence training protocol based on Zohar and Marshall [20], Emmons [21], and Sisk and Torrance. The validity of spiritual intelligence training was confirmed in research performed by Sisk and Torrance [22]. On the other hand, the validity of personal intelligence intervention sessions was confirmed in a study carried out by Martin and Rippon [23]. The implementation of sessions is described in Table 1. The control group received a lecture presented by the researcher on psychiatric signs and symptoms and common terminologies over two 3-hour sessions with an interval of a week.

The package of personal intelligence that has been used in this research includes ten 60-minute sessions. This training package in Iran has been developed and organized by Amram [23].

Social compatibility scale

It was designed as a resultant scale to evaluate the medicinal and psychological therapy of depressed patients. Nowadays, this scale is extensively used to measure the compatibility of patients and healthy individuals. The theoretical basis and the content of the phrases used in the test have been taken from the structured and scaled interview of Gerland in order to evaluate incompatibility and the initial experimental studies conducted by Pekol and Weisman in 1999. This scale evaluates the interpersonal relationships in different roles, such as emotions, satisfaction, difference, and performance [24]. The structure of the test shows two distinctive dimensions: six role areas (persistence, family) and five dimensions of compatibility with appropriate roles specified for each area. The Social Adjustment Scale was initially developed as an interview program and then turned into a self-assessment test. The self-assessment version is useful for the interviewer since it is cost-effective and not influenced by interviewer bias. Both the respondents and their relatives can complete the self-assessment scale. Both the interview and the self-assessment versions include 42 items on how to play a role in six areas, including work (as an employee, housewife or student, items 1-18), leisure-time social activities (items 19-29), extended family relationships (items 30-38), spouse roles

Table 1. Spiritual intelligence training sessions

\begin{tabular}{|c|c|}
\hline Session & Subject \\
\hline Session 1 & $\begin{array}{l}\text { Introducing the overall structure of the sessions, expressed expectations, and regulations. Conducting a pre-test } \\
\text { and getting to know the subject of spirituality, asking a few questions to discuss, and assignment for next week. }\end{array}$ \\
\hline Session 2 & $\begin{array}{l}\text { Familiarity with the application of spirituality in daily life and spiritual intelligence from King's point of view. It is } \\
\text { worth noting that in all the sessions except the tenth session, some questions about the subject of the meeting } \\
\text { were then discussed. The assignment was also given for next week. }\end{array}$ \\
\hline Session 3 and 4 & $\begin{array}{l}\text { Teaching the first and second parts, the first component of King's spiritual intelligence, critical existential thinking } \\
\text { includes: imagining thinking of oneself, defining and exemplifying existential intelligence and existential issues } \\
\text { (the principle of existence, the power of infinity, after death) in collaboration with the participants. Reflection on } \\
\text { the supreme power or God, the origin of being and unity, and being in harmony with the universe. }\end{array}$ \\
\hline Session 5 and 6 & $\begin{array}{l}\text { Teaching the first and second parts, the second component of spiritual intelligence from King's perspective is the } \\
\text { production of personal meaning, including grouping participants for group discussion, exercises, such as defining } \\
\text { the meaning of life and everything that gives meaning to life, writing about life's meaningful experiences and the } \\
\text { ability to find positive meanings. in negative experiences. }\end{array}$ \\
\hline Session 7 & $\begin{array}{l}\text { Teaching the third component of spiritual intelligence from King's perspective: transcendent consciousness, } \\
\text { defining transcendental consciousness from King's Perspective, including allegation of transcendental } \\
\text { consciousness, mindfulness in the inner and outside worlds, presenting experiences of superior realities by } \\
\text { participants. }\end{array}$ \\
\hline Session 8 and 9 & $\begin{array}{l}\text { Teaching the first and second part of the fourth component of spiritual intelligence from King's perspective: } \\
\text { extending the state of consciousness, including explaining and practicing the development of conscious states, } \\
\text { how to practice meditation, mindfulness, and practice, the definition of sleep and its application in daily life. }\end{array}$ \\
\hline Session 10 & $\begin{array}{l}\text { Review past sessions, performing post-test ten days after the end of training programs. It should be noted that } \\
\text { spiritual intelligence and life skills training programs were conducted by the researcher in both groups. }\end{array}$ \\
\hline
\end{tabular}


(items 46-38), parental role (items 50-47), and family unit member (items 51-54). In this questionnaire, there are separate items for the working relationships of housewives and employed people. Therefore, the scale contains 54 final items, and respondents will answer to 42 items according to their conditions. Cronbach's alpha coefficient was reported as 0.47 , and the mean of test reliability was calculated at 0.80 . Moreover, the alpha coefficient for the self-report scale in a study conducted in Japan was 0.73 . In a recent study, depressed patients and non-depressed patients were not significantly different regarding 40 items out of 48 items [25].

Accountability and legitimacy questionnaire

Alipoor validated this scale in 2006 as a resultant scale for assessing liability and legitimacy. It is composed of 50 items and seven factors: Selfmanagement, order, legitimacy, trust, loyalty, organization, and progressivism [26]. The data obtained from the research were analyzed using principal component factor analysis and Varimax rotation. According to the results, the correlation between one by one test of items and the total concept of the test was estimated at 0.87. The validity of the questions through group differences was also assessed on two groups of high and low responsibility using an independent t-test. The results were indicative of significant differences in all seven factors. It signifies that the accountability test was able to distinguish between the two groups and had a high validity. The reliability of the test was re-examined. In calculating the reliability, the Cronbach's alpha coefficient of internal consistency was estimated at 0.94 for the whole questionnaire before the rotation. Nevertheless, after rotating and dropping 28 items, the reliability was obtained at 0.91 [27].

Data collection was conducted in two ways: One part of the data related to the research literature was collected through library study, papers, thesis, journals, and newspapers. The other part was collected using Pekol and Weisman Social Compatibility Questionnaire [24] and Alipoor's [26] Accountability and Legitimacy Questionnaire. Initially, each subject was assigned a number, and participants were randomly allocated to three groups of experimental groups 1 and 2, and the control group. Thereafter, the participants were provided with the aim of the research, and all three groups received the social compatibility questionnaire designed by Pekol and Weissman, and accountability and legitimacy questionnaire developed by Alipour as a pre-test and were asked to express their opinion carefully. In the next step, the experimental groups were subjected to spiritual intelligence and personal intelligence training interventions which were provided by the researcher to increase their adaptability, accountability, and legitimacy. At the end of interventions, the participants in two experimental groups were administered the social compatibility questionnaire and accountability and legitimacy questionnaire as a posttest. Finally, the obtained data were analyzed in SPSS software.

Statistical analysis of covariance was used to determine the effects of the independent variable on the dependent variable. It was the appropriate method for the experimental design of the preposttest with the control group. Moreover, the Kolmogorov-Smirnov test was used to check the

Table 2. Personal intelligence sessions

\begin{tabular}{|c|c|}
\hline Sessions & Titles \\
\hline First & $\begin{array}{l}\text { Performing pre-test, communication, and conceptualization problem. Getting familiar with the topic of personal } \\
\text { intelligence, establishing a relationship and controlling personal emotion- dynamic relation and personal } \\
\text { intelligence. }\end{array}$ \\
\hline Second & $\begin{array}{l}\text { Education and awareness of personality traits based on facial symptoms. Components of establishing } \\
\text { communication, behavioral adaptation and its factors, creative criticism as an important function of } \\
\text { communications. }\end{array}$ \\
\hline Third & $\begin{array}{l}\text { Understanding the reasons and consequences of personal emotion of self and others, personal intelligence, } \\
\text { occupational and professional success, creating skills, facing pain and suffering, and learning how to use } \\
\text { introversion. }\end{array}$ \\
\hline Fourth & $\begin{array}{l}\text { Learning how to label personality traits for yourself and others. The function of personal intelligence, the impact of } \\
\text { personal intelligence on life and health. }\end{array}$ \\
\hline Fifth & $\begin{array}{l}\text { Social capability and listening, social capability and speaking, personal intelligence and group work, } \\
\text { communication and closed conflict, learning how to identify motivations and goals. }\end{array}$ \\
\hline Sixth & $\begin{array}{l}\text { Individual and group personal awareness (self-awareness and social awareness), using personal intelligence in the } \\
\text { work environment and repairing relations, defense awareness training. }\end{array}$ \\
\hline Seventh & $\begin{array}{l}\text { The way to effective use and regulation of emotions of self and others, using personal intelligence for enhancing the } \\
\text { efficacy. Teaching awareness of your personal interests and desires. }\end{array}$ \\
\hline Eighth & $\begin{array}{l}\text { Preventing destructive reaction in front of incentive, correct performance despite exerted pressures, having } \\
\text { endurance. Learning how to make decisions about your personality traits. }\end{array}$ \\
\hline Ninth & $\begin{array}{l}\text { Pattern, model, sample, and control of inclinations managing internal and external relations (self-management and } \\
\text { relationship management). Learning how to find a life orientation. }\end{array}$ \\
\hline Tenth & Review of the last session and conducting posttest. \\
\hline
\end{tabular}


normal distribution of data. Furthermore, Pillai's Trace, Wilk's Lambda, Hoteling's Trace, Roy's Largest Root, and t-test and Matrix $(\mathrm{K})$ and Box test were used in order to investigate the homogeneity of the variance-covariance matrix of the research variables in the research groups.

\section{Results}

The mean (SD) age of participants was reported as $15.2 \pm 3.4, \quad 15.5 \pm 3.7, \quad 15.1 \pm 4.4$ in the spiritual intelligence group, personal intelligence group, and in the control group, respectively. The subjects were within the age range of 14-16 years.

As illustrated in Table 4, considering pre-test scores as covariates, the difference between the scores of spiritual intelligence and personal intelligence in the promotion of students' compatibility was significant at the level of $\mathrm{P} \leq 0.05$. The obtained results indicated the effectiveness of the two therapies regarding student's compatibility. These findings along with the difference between the scores of the two groups suggested that using spiritual intelligence and personal intelligence improved the students' compatibility. Moreover, the effect size was obtained at 0.47 signifying that $0.48 \%$ of the observed changes in the post-test scores of the students were due to spiritual intelligence training programs. The results of the Bonferroni Post-Hoc Test showed the least significant difference in determining the intergroup differences in terms of compatibility pointing to a significant difference between the effectiveness of spiritual intelligence and personal intelligence on adjustment improvement. Therefore, the mean difference between the two groups was estimated at $-3.92(\mathrm{P} \leq 0.05)$. It can be concluded that spiritual intelligence is more effective in the enhancement of compatibility status, compared to personal intelligence.
As displayed in Table 5, considering the pre-test scores as covariates, the difference between the scores of spiritual intelligence and personal intelligence in the improvement of accountability status was significant $(\mathrm{P} \leq 0.05)$. Although the results indicate the effectiveness of the two therapies on the students' accountability, the findings of the present study and the difference between the scores of the two groups denoted that the use of spiritual intelligence concerning personal intelligence improved students' accountability status. In addition, the effect size was calculated at 0.59 suggesting that $0.59 \%$ of the observed changes in post-test scores of accountability status were due to spiritual intelligence intervention. Bonferroni PostHoc Test results for the least significant difference for determining intergroup differences between the groups in the mean score of accountability indicated that there is a significant difference between the effectiveness of spiritual intelligence and personal intelligence in the improvement of accountability status. Therefore, the mean difference between the two groups was obtained at -4.15 and was significant at the level of $(\mathrm{P} \leq 0.05)$. Therefore, it can lead to the conclusion that spiritual intelligence was more effective in the improvement of accountability, compared to personal intelligence.

The results presented in Table 6 show that considering pre-test scores as co-variate variables, there is a significant difference between the scores of spiritual intelligence and personal intelligence in the improvement of students' legitimacy status at the level of $(\mathrm{P} \leq 0.05)$. Although the results indicated the effectiveness of two therapies on students' legitimacy, the findings of the present study and the difference between the scores of the two groups suggested that the use of spiritual intelligence and personal intelligence improved the

Table 3. Mean and standard deviation among the study groups

\begin{tabular}{|c|c|c|c|c|c|c|c|c|c|c|c|c|c|}
\hline \multirow{3}{*}{ Variable } & \multirow{3}{*}{ Dimensions } & \multicolumn{4}{|c|}{ Control group } & \multicolumn{4}{|c|}{ Spiritual intelligence group } & \multicolumn{4}{|c|}{ Personal intelligence group } \\
\hline & & \multicolumn{2}{|c|}{ Pretest } & \multicolumn{2}{|c|}{ Posttest } & \multicolumn{2}{|c|}{ Pretest } & \multicolumn{2}{|c|}{ Posttest } & \multicolumn{2}{|c|}{ Pretest } & \multicolumn{2}{|c|}{ Posttest } \\
\hline & & $M$ & SD & $M$ & SD & $M$ & SD & M & SD & $M$ & SD & $M$ & SD \\
\hline \multirow{2}{*}{ Compatibility } & Compatibility & 17.1 & 5.2 & 17.1 & 5.2 & 17.2 & 4.6 & 23.4 & 5.1 & 17.2 & 4.6 & 24.5 & 5.2 \\
\hline & Social continuity & 17.1 & 5.3 & 17.1 & 5.3 & 17.1 & 4.7 & 22.8 & 5.1 & 18.1 & 4.8 & 23.8 & 5.1 \\
\hline \multirow{5}{*}{ Accountability } & Economic & 11.3 & 3.2 & 10.1 & 4.1 & 10.2 & 4.2 & 10.1 & 4.1 & 10.2 & 4.2 & 12.1 & 3.1 \\
\hline & Social & 21.3 & 6.9 & 22.1 & 6.1 & 21.3 & 6.2 & 28.1 & 4.1 & 20.3 & 4.1 & 29.1 & 5.1 \\
\hline & Legal & 21.2 & 3.6 & 21.1 & 4.5 & 17.3 & 4.8 & 24.1 & 5.4 & 20.3 & 4.8 & 23.1 & 5.1 \\
\hline & Moral & 18.6 & 5.1 & 18.4 & 4.9 & 23.2 & 7.1 & 21.1 & 7.3 & 17.2 & 7.1 & 20.1 & 7.3 \\
\hline & Charity & 22.6 & 7.5 & 23.1 & 8.1 & 17.4 & 6.4 & 27.6 & 5.8 & 23.4 & 6.4 & 27.6 & 5.2 \\
\hline \multirow{2}{*}{ Legitimacy } & Legitimacy & 17.2 & 5.2 & 17.1 & 5.2 & 17.2 & 4.6 & 22.5 & 6.1 & 17.1 & 4.8 & 23.6 & 5.1 \\
\hline & Continuity of system & 17.1 & 5.3 & 17.1 & 5.3 & 17.1 & 4.8 & 21.8 & 6.1 & 17.3 & 4.8 & 22.4 & 5.6 \\
\hline
\end{tabular}

Table 4. Results of covariance analysis for comparison of compatibility in spiritual intelligence and personal intelligence training groups

\begin{tabular}{lcccccc}
\hline Source of changes & Sum of squares & df & Mean of squares & F & Level of sig. & Eta \\
\hline Model & 166.43 & 1 & 166.43 & 18.21 & 0.001 & 0.06 \\
Group & 1262.35 & 1 & 2526.62 & 142.83 & 0.001 & 0.48 \\
Error & 7.82 & 33 & 748.72 & & & \\
\hline
\end{tabular}


Table 5. Results of the analysis of covariance for comparing accountability in spiritual intelligence and personal intelligence training groups

\begin{tabular}{lcccccc}
\hline Source of changes & Sum of squares & df & Mean of squares & $\mathbf{F}$ & Level of significance & Eta \\
\hline Model & 92.84 & 1 & 92.84 & 27.67 & 0.001 & 0.00 \\
Group & 321.64 & 1 & 645.08 & 98.43 & 0.001 & 0.59 \\
Error & 3.25 & 33 & 278.54 & & & \\
\hline
\end{tabular}

Table 6. Results of Covariance Analysis for Comparison of Legitimacy in Spiritual and Personal Intelligence Training Groups

\begin{tabular}{lcccccc}
\hline Source of changes & Sum of squares & df & Mean of squares & F & Level of significance & Eta \\
\hline Model & 166.43 & 1 & 166.43 & 18.21 & 0.001 & 0.06 \\
Group & 1262.35 & 1 & 2526.62 & 142.83 & 0.001 & 0.48 \\
Error & 7.82 & 33 & 748.72 & & & \\
\hline
\end{tabular}

size was reported as 0.48 implying that $0.48 \%$ of the observed changes in post-test scores of students' legal status were due to spiritual intelligence intervention programs. Furthermore, Bonferroni Post-Hoc Test results and the least significant difference for determining the intergroup differences in the mean score of legitimacy showed that there is a significant difference between the effectiveness of spiritual intelligence and personal intelligence regarding the improvement of the legitimacy. The mean difference between the two groups was measured at -3.90 which is significant at the level of $(\mathrm{P} \leq 0.05)$. It leads to the conclusion that spiritual intelligence was more effective in the enhancement of legitimacy status, compared to personal intelligence.

\section{Discussion}

The results showed that there is a significant difference between the effect of spiritual intelligence and personal intelligence training on increasing students' compatibility. The obtained results were in line with studies carried out by Hosseini et.al [28], Charkhabi et.al [29], Abdullah et.al [30], and Animasahun et.al [31]. In a similar vein, these studies pointed to the peculiar role of spiritual intelligence and personal intelligence in the creation and enhancement of students' compatibility, as well as the ability to solve their life problems. In testing the mentioned hypothesis, the difference between the scores of the two groups suggested that using spiritual intelligence and personal intelligence improved students' compatibility.

Moreover, the effect size was obtained at 0.48 signifying that $0.48 \%$ of the observed changes in the post-test scores of students' compatibility were due to the intervention. Moreover, the mean difference between the two groups was calculated at -0.90 which was significant al the level $(\mathrm{P} \leq 0.05)$. Therefore, it points to the conclusion that spiritual intelligence is more effective in the enhancement of compatibility, compared to personal intelligence. This result can be justified on the ground that people need to know the best and most practical way to deal with a problem to be compatible with life. These goals can be achieved better and easier with the help of spiritual intelligence training [30]. Personal intelligence training also uses a variety of cognitive-behavioral techniques and is considered a part of social skills training that is designed primarily to help individuals avoid the barriers and anxiety that arise in the various stages of personal life. Moreover, this kind of training equips people with specifics skills to develop desirable social functioning in the family and environment [14]. Therefore, it can be inferred that spiritual intelligence and personal intelligence training can play a significant role in the enhancement of compatibility. Nevertheless, the role of spiritual intelligence was more prominent in the present research. Therefore, the results demonstrated that there is a significant difference between the effectiveness of spiritual intelligence and personal intelligence training in terms of the promotion of students' compatibility.

The results of multivariate analysis of variance revealed that the difference between the scores of the two groups regarding the use of spiritual intelligence and personal intelligence improved accountability. Moreover, the effect size was calculated at 0.59 suggesting that $0.59 \%$ of the changes observed in the posttest scores of accountability were due to the intervention. Furthermore, the mean difference between the two groups was obtained at $-4.15 \quad(\mathrm{P} \leq 0.05)$. Consequently, it can be inferred that there is a significant difference between spiritual intelligence and personal intelligence in increasing students' accountability. It can be argued that spiritual intelligence is a step-by-step, purposeful, efficient, and orderly process. This ability is a cognitivebehavioral process that is an intrinsic commitment on the part of the individual in order to efficiently perform all of the activities assigned to him/her. Spiritual intelligence, as the basis of one's beliefs, affects performance in such a way that it shapes the real form of life.

In Islam, spiritual intelligence has implicitly received assiduous attention. Among the factors affecting 
spiritual intelligence in Islamic texts, we can mention piety and virtue, along with daily exercises, such as meditation on creation, a meditation on creatures, fasting, prayers, reading the Qur'an, and sincere contemplation in its verses [18]. Spiritual intelligence teaches people compassion, kindness, integration regarding differences, and reliance on meaning [19]. In this regard, the personal intelligence training program is performed to foster capability and daring behaviors so that people can be self-sufficient by developing a positive outlook. Personal intelligence training at both individual and social levels has been shown to bring about dramatic and positive effects; therefore, teaching this ability to people in society is of paramount importance [22]. Spiritual intelligence and personal intelligence can contribute significantly to the enhancement of accountability. Nonetheless, as indicated in the current study, spiritual intelligence had a more prominent role in this regard, compared to personal intelligence. Therefore, the results denoted that there is a significant difference between spiritual intelligence and personal intelligence training concerning the enhancement of students' accountability.

Finally, the result showed that there is a significant difference between spiritual intelligence training and personal intelligence training in terms of increasing students' legitimacy. Spiritual intelligence and personal intelligence training played a key role in students' adherence to legitimacy and also led to an increase in leadership and guidance. In the abovementioned hypothesis, the difference between scores of the two groups indicated that using spiritual intelligence and personal intelligence improved students' legitimacy. Moreover, the effect size was obtained at 0.48 signifying that $0.48 \%$ of observed changes in the post-test scores of students' legitimacy were due to the intervention. Furthermore, the mean difference between the two groups was reported as -3.90 which was significant at the level of $(\mathrm{P} \leq 0.05)$. Therefore, it can be inferred that spiritual intelligence is more effective in the improvement of legitimacy, in comparison with personal intelligence. This finding can be justified on the ground that in order to live a thoughtful life, people should know that in the face of life problems, the wisest things to do are: planning, organizing, commanding, directing, guiding, supervising, controlling, deciding, and managing. These goals can be attained better and easier with the help of spiritual intelligence training [24]. Personal intelligence training also uses a variety of cognitive-behavioral techniques, such as selfcontrol, self-management, self-regulation, selfdirection, self-restraint, patience, and self-sacrifice.
It is regarded as a part of the legitimacy skill training that is primarily designed to help individuals prevent obstacles, disorders, confusion, chaos, and commotion in various aspects of personal and social life. Therefore, it can be stated that spiritual intelligence and personal intelligence training can play a significant role in the promotion of legitimacy. However, in the current study, spiritual intelligence had a more powerful impact. The results illustrated that there is a significant difference between spiritual intelligence training and personal intelligence training regarding the promotion of students' legitimacy.

The results of the present study confirmed the effectiveness of spiritual intelligence and personal intelligence training in the improvement of compatibility, accountability, and legitimacy of students. Based on the obtained results, it can be argued that spiritual intelligence and personal intelligence intervention programs enhance selfregulation, self-management, self-control, selfmonitoring, self-efficacy, adaptability, and higher family continuity. Moreover, these training programs can resolve individual and extrinsic conflicts among experimental group participants, compared to their counterparts in the control group. In general, spiritual intelligence and personal intelligence training can exert significant effects on the enhancement of compatibility or adaptability, accountability, and legitimacy in students. However, in a two-by-two comparison of interventional methods, spiritual intelligence training was better able to influence and modify the status of compatibility and accountability. Therefore, it has more dramatic effects on the enhancement of cognitive flexibility, accountability, social interactions, and maintenance of order and discipline among students, in comparison with personal intelligence.

Every study has some limitations which must be addressed in the paper. The remarkable limitations of this study are as follows: the researchers had difficulty in obtaining necessary permits and coordinating with the Department of Education. Moreover, the research was conducted only in Guilan which imposes some limitations on generalizing the obtained results to other cities and regions in the country. Convenience and voluntary sampling is also another limitation of the present research.

Since spiritual intelligence training is more effective in the enhancement of compatibility, accountability, and legitimacy of students, it is suggested that further studies be carried out to achieve total unity by preparing an educational package. The application of the spiritual intelligence approach should be made along with other psychological 
training packages on all kinds of incompatibility, lack of accountability, and lack of legitimacy as research projects. Furthermore, it is recommended that the present research be conducted in a larger community at the national level. To generalize the results, the current study should be repeated in other cities regarding subcultures and minorities in Iranian society. Equally important, it is suggested that developing a spiritual intelligence training program for students may be of great help in the enhancement of compatibility, accountability, and legitimacy. Furthermore, according to the results of the present research, designing a personal intelligence education program for maladaptive students can effectively increase their compatibility, accountability, and legitimacy. Moreover, different educational courses are recommended to increase the compatibility, accountability, and legitimacy of students. In addition, a variety of programs should be implemented to increase the level of psychological antecedents of life skills and accountability. Life skills workshops led by professionals, administrators, and educators in schools and universities can be also effective in the prevention of educational problems in the future. Finally, educational authorities should increasingly commit to universalize group education services, such as life skills training.

\section{Conclusions}

The results of the current study pointed to the conclusion that spiritual intelligence and personal intelligence training increased the compatibility, accountability, and legitimacy of 14-16-year-old students.

\section{Compliance with ethical guidelines}

All ethical principles were considered in the current study. The participants were informed about the purpose of the research and its implementation stages and signed the informed consent. They were also assured of the confidentiality of their information. Moreover, they were allowed to leave the study whenever they wish, and if desired, the results of the research would be available to them. The authors' deepest appreciation goes to all students who participated in this research project. The present article was extracted from the first author's doctoral dissertation approved by the Ethics Committee of Ardabil University of Medical Sciences (IR.ARUMS.REC.1398.021).

\section{Funding/Support}

This research did not receive any specific grant from funding agencies in the public, commercial, or not-for-profit sectors.

\section{Conflicts of Interest}

The authors declare that they have no conflict of interest regarding the publication of the current article.

\section{References}

1. Alexander NA, Jang ST, Kankane S. The performance cycle: the association between student achievement and state policies tying together teacher performance, student achievement, and accountability. American Journal of Education. 2017; 123(3):413-46. [DOI:10.1086/691229]

2. Chan AW, Siu AF. Application of the spiritual intelligence self-report inventory (SISRI-24) among Hong Kong university students. International Journal of Transpersonal Studies. 2016; 35(1):3.

3. Devi RK, Rajesh NV, Devi MA. Study of spiritual intelligence and adjustment among arts and science college students. Journal of Religion and Health. 2017; 56(3):82838. [DOI:10.1007/s10943-016-0225-8] [PMID]

4. Dodds A, Kodate N. Accountability, organisational learning and risks to patient safety in England: conflict or compromise? Health, Risk \& Society. 2011; 13(4):327-46. [DOI:10.1080/13698575.2011.575454]

5. Esmaeelinezhad O, Boerhannoeddin AB, Singaravelloo K. The effects of corporate social responsibility dimensions on employee engagement in Iran. International Journal of Academic Research in Business and Social Sciences. 2015; 5(3):261. [DOI:10.6007/IJARBSS/v5-i3/1517]

6. Ferreira C, Schulze S. Facilitating spiritual intelligence in South African secondary school learners. Koers. 2015; 80(2):1-8.

7. Gameroff MJ, Wickramaratne P, Weissman MM. Testing the short and screener versions of the social adjustment scaleself-report (SAS-SR). International Journal of Methods in Psychiatric Research. 2012; 21(1):52-65. [DOl:10.1002/ mpr.358] [PMID] [PMCID]

8. Henderson A, Tyler S. Facilitating learning in clinical practice: evaluation of a trial of a supervisor of clinical education role. Nurse Education in Practice. 2011; 11(5):288-92. [DOI:10.1016/j.nepr.2011.01.003] [PMID]

9. Hutt EL, Gottlieb J, Cohen JJ. Diffusion in a vacuum: edTPA, legitimacy, and the rhetoric of teacher professionalization. Teaching and Teacher Education. 2018; 69:52-61. [DOI:10.1016/j.tate.2017.09.014]

10. Keddie A. Student voice and teacher accountability: possibilities and problematic. Pedagogy, Culture \& Society. 2015; 23(2):225-44. [DOI:10.1080/14681366.2014.977806]

11. Malik MS, Tariq S. Impact of spiritual intelligence on organizational performance. International Review of Management and Marketing. 2016; 6(2):289-97.

12. Marsh JA, Farrell CC, Bertrand M. Trickle-down accountability: how middle school teachers engage students in data use. Educational Policy. 2016; 30(2):243-80. [DOI:10.1177/0895904814531653]

13. Martinez BB, Custodio RP. Relationship between mental health and spiritual wellbeing among hemodialysis patients: a correlation study. Sao Paulo Medical Journal. 2014; 132(1):237. [DOI:10.1590/1516-3180.2014.1321606] [PMID]

14. Mohammadi H, Bahreinian A, Mortazavi MA, Mousavi MR, Ashrafnezhad Z. The effect of training spiritual Intelligence on the mental health of male high school students. Journal of Research on Religion \& Health. 2015; $1(1): 28-39$

15. Mousavi SH, Talebzadeh NM, Shams MG. The relationship between spiritual intelligence and organizational citizenship behavior high school teachers in Zanjan. Quarterly Educational Psychology. 2012; 7(22):65-94.

16. Nejati $M$, Ghasemi S. Corporate social responsibility in Iran from the perspective of employees. Social Responsibility Journal. 2012; 8(4):578-88. [DOI:10.1108/1747111121 1272552]

17. Perry C, Henderson A, Grealish L. The behaviours of nurses that increase student accountability for learning in clinical practice: an integrative review. Nurse Education Today. 2018; 65:177-86. [DOI:10.1016/j.nedt.2018.02.029] [PMID]

18. Partovi A, Boland $H$. Relationship between spiritual intelligence and resilience to the mothers' stress and neonatal anthropometric indices. International Journal of Humanities and Cultural Studies. 2016; 1(1):732-41.

19. Ramnanan CJ, Pound LD. Advances in medical education and practice: student perceptions of the flipped classroom. Advances in Medical Education and Practice. 2017; 8:63- 
73. [DOI:10.2147/AMEP.S109037] [PMID] [PMCID]

20. Reisig MD, Bain SN. University legitimacy and student compliance with academic dishonesty codes: A partial test of the process-based model of self-regulation. Criminal Justice and Behavior. 2016; 43(1):83-101. [DOI:10.1177/ 0093854815611165]

21. Zohar D, Marshall I, Marshall IN. SQ: connecting with our spiritual intelligence. New York: Bloomsbury Publishing USA; 2000.

22. Emmons RA. Is spirituality an intelligence? Motivation, cognition, and the psychology of ultimate concern. The International Journal for the Psychology of Religion. 2000; 10(1):3-26. [DOI:10.1207/S15327582IJPR1001_2]

23. Martin M, Rippon J. Teacher induction: personal intelligence and the mentoring relationship. Journal of InService Education. 2003; 29(1):141-62. [DOI:10.1080/ $13674580300200204]$

24. Sisk DA, Torrance EP. Spiritual intelligence: developing higher consciousness. New York: Creative Education Foundation Press; 2001.

25. Stein RE, Colyer CJ, Manning J. Student accountability in team-based learning classes. Teaching Sociology. 2016; 44(1):28-38. [DOl:10.1177/0092055X15603429]

26. Fard HD, Rostamy AA. Promoting public trust in public organizations: explaining the role of public accountability. Public Organization Review. 2007; 7(4):331-44.
[DOI:10.1007/s11115-007-0041-4]

27. Strasser R, Hogenbirk JC, Minore B, Marsh DC, Berry S Mccready WG, et al. Transforming health professional education through social accountability: Canada's Northern Ontario School of Medicine. Medical Teacher. 2013; 35(6):490-6. [DOI:10.3109/0142159X.2013.774334] [PMID]

28. Hosseini M, Elias H, Krauss SE, Aishah S. A review study on spiritual intelligence, adolescence and spiritual intelligence, factors that may contribute to individual differences in spiritual intelligence and the related theories. Journal of Social Sciences. 2010; 6(3):429-38.

29. Charkhabi M, Mortazavi A, Alimohammadi S, Hayati D. The effect of spiritual intelligence training on the indicators of mental health in Iranian students: an experimental study. Procedia-Social and Behavioral Sciences. 2014; 159:355-8. [DOI:10.1016/j.sbspro.2014.12.387]

30. Abdullah F. Teaching Islamic ethics and ethical training: benefiting from emotional and spiritual intelligence. International Journal of Humanities and Social Science. 2012; 2(3):224-32.

31. Animasahun RA. Intelligent quotient, emotional intelligence and spiritual intelligence as correlates of prison adjustment among inmates in Nigeria prisons. Journal of Social Sciences. 2010; 22(2):121-8. [DOI:10.1080/09718923. 2010.11892792 